\title{
O USO DO C.M.U. COMO ERVICIDA TOTAL (*). R.
} Forster. C.M.U. é a abreviatura usada para designar um produto químico ervicida, fabricado pela E.I. du Pont de Nemours, visando aplicação agrícola e industrial. Trata-se de um derivado da uréia, 3 - (p-clorofenil) - 1,1 dimetiluréia $\left({ }^{1}\right)$, apresentado na forma de pó molhável a $80 \%$ de concentração. Recebemos por gentileza de W. H. Tisdale $\left({ }^{2}\right)$, consultor técnico da citada firma, pequena quantidade para uso experimental.

Pelos primeiros resultados e recomendações $(1,2,3)$ o C.M.U. poderia ser testado em doses baixas, até $0,025 \mathrm{~g} / \mathrm{m}^{2}$ (aproximadamente $1 / 4 \mathrm{lb} /$ acre) quando para aplicação em pré-emergência, ou então, em doses elevadas que atingiriam a $8 \mathrm{~g} / \mathrm{m}^{2}$ (aproximadamente $80 \mathrm{lb} /$ acre), no caso de ervas perenes ou ao se pretender esterilização do solo por longo prazo. Os primeiros resultados $\left(^{1}\right)$ foram conseguidos não só contra gramíneas e dicotiledôneas em geral, como também contra a tiririca.

APLICAÇÃO. A tiririca (Cyperus rotundus L.), em condições as mais diver'sas, é uma das ervas más que infestam grandes áreas no Estado de São Paulo, constituindo um dos maiores problemas a sua erradicação. Natural que, de início, fôsse também tentado contra essa planta infestante o uso do C.M.U.. Como a tiririca apresenta forma de resistência, constituída pelos tubérculos subterrâneos, o seu combate se torna, por isso mesmo, mais difícil. Todavia, já nas primeiras publicações era mencionado que o C.M.U. age pelas raízes $\left(^{1}\right)$, motivo pelo qual seria recomendável contra plantas como a tiririca. Esta ciperácea não tem crescimento de porte alto, pelo que, em terrenos muito infestados de outras ervas más, pode ser encoberta nos períodos quando a vegetação destas é mais intensa, tornando ainda maior o problema de esterilização do chão, contra sua infestação.

MATERIAL E MÉTODO. Escolhemos um terreno na Estação Experimental Central do Instituto Agronômico, em terra roxa-misturada, onde, além da tiririca, se encontravam também outras ervas infestantes, e entre estas o capim-marmelada (Brachiaria plantaginea, (Link) Hitchc.), o carrapicho (Cenchrus sp.), o carrapicho-de-carneiro (Acanthospermum hispidum L.), o capim-colchão (Digitaria sanguinalis (L.) Scop.) e o capim-favorito (Rhynchelytrum roseum (Nees) Stapf et Hubb.). Foi marcada uma série

(*) Iaceidila para publicașão em 3 de oltubro de 1957.

(1) BUCHA, H. C. \& TODD, C. W. 3-(p-Chlorophenyl)-1,1 Dimethylurea. A new herbicide. Science 114:493-494. 1951.

(2) TISDALE, W. H. Informações gerais para emprêgo de C.M.U., 1952. [Comunicaçäo escrita]

(3) E. I. DU PONT DE NEMOURS \& CO. Nuevo matamalezas quimico. Bol.. Agricultor $9(3): 11-13.1952$. 
de canteiros quadrados com $3 \mathrm{~m}$ de lado cada, divididos em três sub-canteiros, dos quais a parte I, constituída da metade do canteiro $(3 \times 1,5 \mathrm{~m})$, capinada a enxada e o chão nivelado, em II, abrangendo a quarta parte $(1,5 \times 1,5 \mathrm{~m})$, as ervas, eom exceção da tiririca, foram arrancadas a mão, e em III, na outra quarta parte, a vegetação original já mencionada permaneceu intacta. Pretendia-se, assim, conhecer também da necessidade do preparo prévio do terreno.

DOSES. Como se objetivava despraguejamento total da área, foram empregadas as doses da $1,3,5,7$ e $9 \mathrm{~g} / \mathrm{m}^{2}$, mantendo-se um canteiro testemunha, sem C.M.U. Foi feita aplicação das doses citadas diluídas em 1 litro de água por canteiro de $9 \mathrm{~m}^{2}$, utilizando-se, para êsse fim, de pulverizador manual provido de bico comum de jato cônico, de sorte a se empregar quantidade normal de água.

RESULTADOS. O tratamento dos canteiros foi efetuado em 18-12-53, estando o chão úmido. Seis dias depois da aplicação já o capim marmelada e o carrapicho apresentavam as margens, assim como os ápices das fôlhas, requeimados. Êsses sintomas se generalizavam, em geral precedidos por amarelecimento; com o passar do tempo se agravavam, secando finalmente tôda a vegetação.

Nas áreas capinadas dos canteiros onde havia ficado sòmente a tiririca, não voltou sementeira de ervas anuais, mantendo-se o chão limpo, por tempo aproximado de dois anos. Quanto à tiririca, apresentou amarelecimento progressivo das fôlhas, que secavam após seis semanas; depois disso, podia-se observar que apresentava rebrotas, com fôlhas aparentemente sadias, mas logo em seguida estas mostravam também sinais de amarelecimento, isto é, as plantas que brotavam na superfície do solo não conseguiam sobreviver. Compreende-se tal fato, uma vez que no local do ensaio, segundo constatações anteriores, as "batatinhas" da tiririca atingiam até $20 \mathrm{~cm}$ de profundidade, apresentando-se, todavia, em maior quantidade na camada até 10 centímetros de profundidade. As "batatinhas" mais profundas naturalmente demoravam mais para fazer suas fôlhas atingir a superfície, isto é, a camada de terra onde havia C.M.U., de modo que as fôlhas podiam atingir o exterior antes de entrarem em contato com o ervicida que ali se encontrava. Aliás, segundo Haun e Peterson $\left({ }^{4}\right)$ a translocação dêsse ervicida no sentido ascendente, para o ápice, é rápida, pois se processa pelo xilema, ao passo que é nula na direção contrária, descendente. Dessa maneira pode ser explicado porque as fôlhas de tiririca chegam a atravessar a camada atingida pelo C.M.U. até à superfície, para só então manifestarem os sintomas de toxidez.

Transcorreram assim quase dois anos (até outubro de 1955) antes de começarem a se estabelecer nas áreas tratadas as primei-

(4) HAUN, J. R. \& PETERSON, J. H. Translocation of 3-(p-Chlorophenyl)-1,1 Dimethylurea in plants. Weeds $3: 177-187.1954$. 
ras plantas, tais como grama-sêda ou poucas plantas de capim-favorito, as duas gramíneas invasoras dominantes existentes nas proximidades de onde estavam localizados os canteiros. Posteriornente, em 28-2-56, procedeu-se à contagem da tiririca que conseguiu sobreviver nos canteiros, tendo-se obtido os resultados que figuram no quadro 1.

QUADRO 1.-Touceiras de tiririca (Cyperus rotundus, L.) contidas num círculo de $35 \mathrm{~cm}$ de diâmetro, nas três regióes de cada canteiro tratado com diferentes doses de C.M.U. 26 meses após a aplicação dos tratamentos

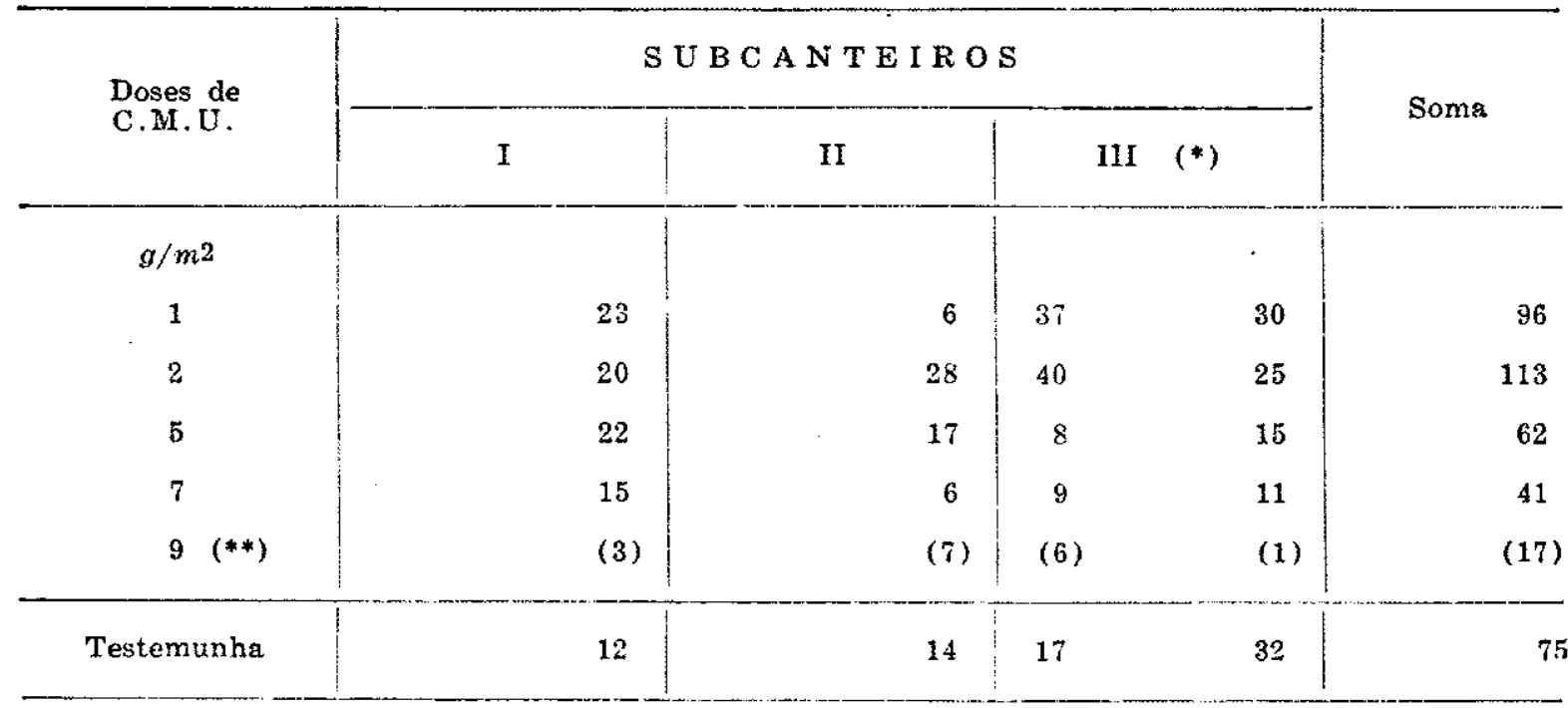

(*) 2 amostras contadas.

(**) Os números entre parêntesis representam a infestação total de cada área e não apenas num círculo de $35 \mathrm{~cm}$ de diâmetro, como para as demais amostragens.

Para o tratamento com $9 \mathrm{~g} / \mathrm{m}^{2}$, a contagem foi feita na área total de cada um dos três sub-canteiros; para os demais tratamentos, fêz-se a contagem das touceiras contidas num círculo de $35 \mathrm{~cm}$ de diâmetro, tomando-se uma amostra para cada sub-canteiro. Portanto, o número 17 na última coluna do quadro 1 representa o total de plantas em $9 \mathrm{~m}^{2}$; para exprimir a população infestante proporcionalmente à área das amostras, teríamos que dividir 17 por 23,7, aproximadamente, que é a proporção de 4 vêzes o $\operatorname{arco}$ de $35 \mathrm{~cm}$ de diâmetro para $9 \mathrm{~m}^{2}$ o que daria um total de 0,71 plantas para a amostra, para comparação com os resultados das doses menores.

Loustalot e outros $\left(^{5}\right)$ já haviam afirmado que o melhor resultado contra a tiririca se obtinha para "batatinhas" existentes no solo, até aproximadamente $10 \mathrm{~cm}$ de profundidade. Pelos resultados apresentados por êsses autores, inclusive quando plantaram tiririca a diversas profundidades, se verifica que o C.M.U. não se movimenta além de $10 \mathrm{~cm}$ de profundidade. Conquanto pelos resultados por nós obtidos possa ser notada sensível redução da

(5) LOUSTALOT A. J.; CRUZADO H. J. \& MUZIK, T. J. Effect of CMU on Nutgrass (Cyperus rotunds. L.) Weeds $2: 196-201$. 1953 . 
vegetação da tiririca, é verdade que ainda algumas plantas permaneceram vivas, mesmo com a aplicação de $9 \mathrm{~g} / \mathrm{m}^{2}$. A aparente desuniformidade dos números apresentados deve ser explicada por se ter tratado de infestação natural na área em aprêço, portantó variável a cada passo. Por isso os resultados das doses crescentes de C.M.U. não devem ser tomados em números absolutos, por provirem de população sabidamente desuniforme. Portanto, os resultados da ação do C.M.U. devem ser comparados com os do canteiro testemunha (sem tratamento). Como havia chovido suficientemente, o trabalho de nivelamento da terra, nos primeiros centímetros pelo menos, não contribuiu para melhorar a ação do C.M.U.. O maior efeito deve ser atribuído, de fato, à umidade que existia em quantidade suficiente no terreno, naquela ocasião.

A maior ou menor penetração do C.M.U. no solo parece depender da movimentação da água, que arrasta consigo o ervicida. A eficiência está, portanto, em estreita dependência da queda pluviométrica. Segundo constatação de Sherburne e outros $\left(^{(}\right)$, essa movimentação é maior em solos arenosos do que em solos argilosos.

As observações por nós realizadas nos levam a aceitar o C.M.U. como ervicida de ação total. Quando aplicado em doses elevadas, é eficaz contra sementeiras de plantas, anuais, pois que, após 24 meses, ainda se mostra baixíssima a infestação de ervas más.

Isso torna o C.M.U. de eficiente emprêgo em áreas onde se pretende demorada esterilização. Quando aplicado em pátios de terra, em doses elevadas, é eficaz mesmo contra plantas de hábito perene, como a grama-sêda e a tiririca, se bem não se tenha conseguido, segundo as observações aqui relatadas, erradicação absoluta da tiririca.

A ação do C.M.U. como esterilizante também se mostra eficiente por não ser necessário o preparo prévio do chão, descle que haja umidade suficiente para ser arrastado às raízes das plantas, o que é interessante no caso de aceiros, ao longo das cêrcas, ou nos leitos de estradas de ferro.

Do ensaio efetuado pode-se aceitar o C.M.U. como erbicida de ação total, recomendável seu uso para esterilização do chão, em locais onde não leva existir vegetação, como sejam pátios para depósitos, sem que para sua aplicação haja necessidade de aração prévia do chão, podendo ser aplicado dissolvido em água, com auxílio de um pulverizador comum. ESTAÇÃO EXPERIMENTAL CENTRAL DO INSTITUTO AGRONÔMICO. 


\section{C.M.U. AS A GENERAL HERBICIDE, FOR SOIL STERILIZATION}

\section{S U M M A R Y}

C.M.U. has been tested in clay soil, where a few annual and perennial weeds were present. Application was made as a water spray, using from 1 to $9 \mathrm{~g}$ per square meter giving as result a gradually increased effect. On the highest level the soil remained sterilized against weed growth for a period of two years. After this period the first Bermuda grass started to grow on the soil. Counts of nut grass proceeded twenty six months after C. M. U. has been applied showed reduction of nut grass to two plants per square meter, compared to the check where still 196 plants of nut grass could be found.

C.M.U. is therefore recommended for sterilization of soll for the purpose of eliminating plant growth. 